Special Issue of the 8th International Advances in Applied Physics and Materials Science Congress (APMAS 2018)

\title{
Investigation of Wear Properties of Toughened Epoxy Resin using Silane Terminated Urethane
}

\begin{abstract}
İ. KARTAL*
Marmara University, Department of Metallurgy and Material Engineering, İstanbul, Turkey

In this study, wear properties of toughened epoxy polymer using a silane terminated urethane were investigated. With this aim, epoxy-based hybrid materials with various concentrations were prepared from bisphenol A-type epoxy resin and a silane terminated urethane. It was presented that in addition to a dispersed second phase formation, an interpenetrating network (IPN) structure was also be formed through the addition of silane terminated urethane. Firstly, silane including inorganic part was synthesized from poly(hexamethylene carbonate) diol and 3-isocyanatopropyl trimethoxysilane. The solutions were mixed with epoxy mixture to obtain hybrid solutions. Various hybrid solutions were prepared using different epoxy/inorganic part solution compositions. The effects of IPN on the wear properties of hybrids were investigated.
\end{abstract}

DOI: 10.12693/APhysPolA.135.1100

PACS/topics: epoxy, wear, interpenetrating network (IPN), composite

\section{Introduction}

Epoxies are a class of thermosetting polymers. Epoxies are used in a wide range of applications such as adhesives, sealants, coatings, paints, and matrices of polymer based composites [1-3]. Un-modified epoxy resins are generally brittle and exhibit low elongation after cure. These polymers usually craze on their free surfaces and the crazed areas are converted into cracks, which propagate with brittle energy absorption resulting in fracture [4]. Several attempts have been made to improve fracture resistance of epoxies [5]. These are as follows: (a) having a more flexible backbone through chemical modification, (b) increasing the molecular weight, (c) lowering the cross-link density, (d) incorporation of a dispersed soft phase which toughens the cured epoxy (e) addition of inorganic fillers/reinforcements into the pure epoxy resin [6]. A more recent method to improve the toughness off brittle polymers is interpenetrating network (IPN) grafting approach. It has been found that the mechanical properties of polymer materials with an IPN structure are fairly superior to those of ordinary polymers. Such improvement is generally believed to stem from an increase in crosslinking density within IPNs [5, 7]. The most important advantage of IPNs is that they can combine the properties of two different chemical structures. Another important feature is that IPNs are not soluble in any solvent, only swell [8-9].

The aim of the present work is to investigate the abrasion properties of toughened epoxy polymer using a silane terminated urethane. Epoxy-based hybrid materials with various concentrations were prepared from bisphenol A-type epoxy resin and a silane terminated

*e-mail: ilyaskartal@marmara.edu.tr urethane. The effects of silane terminated urethane content on the Izod impact and wear properties of hybrids were investigated.

\section{Materials and method}

\subsection{Materials}

Epoxy resin (epikote 828) and its hardener (epicure 205) were provided by Izomas Chemical, Turkey. As a catalyst for the crosslinking reactions of epoxy resin, N,N-dimethylbenzoylamine, poly(hexamethylene carbonate) diol, 3-isocyanatopropyltrimethoxysilane (ICPTMS), tetraethoxysilane (TEOS), ethanol, p-toluenesulfonic acid (PTSA, catalyst), dibutyltin dilaurate (catalyst) and dimethyl acetamide (as a co-solvent) were purchased from Aldrich.

\subsection{Preparation of epoxy-silane terminated urethane solutions and specimens}

Poly(hexamethylene carbonate) diol and 3-isocyanatopropyltrimethoxysilane were charged. Dibutyltin dilaurate, at a concentration of $0.5 \%$, was added as a catalyst. Pre-hydrolyzed TEOS added to above solution before mixing with catalysed epoxy. Epikote 828 was used as the matrix material and Epicure 205 was used as liquid hardener. The liquid hardener was slowly added to the epoxy resin. Then, previously prepared solutions of inorganic part (silane terminated urethane (STU) and pre-hydrolyzed TEOS) were mixed with epoxy-hardener mixture to obtain hybrid solutions. The silane terminated urethane solution was added into the stirred epoxy-hardener mixture. Finally, $1 \%$ by weight of benzyl dimethyl amine (BDMA) was added as a catalyst. There are 5 different compositions in which the inorganic component is varied at $0,5,10,15$ and $20 \mathrm{wt} \%$. Wear properties of the samples were used taber abrasion tester (CS 10 abrasive, ASTM D4060). Izod impact test was conducted by using Zwick B5113.30 using 5.4 J Izod striker. 


\section{Results and discussion}

In this study various hybrid solutions were prepared using different epoxy/inorganic part solution compositions. While creating own network structure of epoxy resin, added silane terminated urethane + pre-hydrolyzed TEOS was formed their own network structure.

Izod impact strength values of the unnotched specimens were given in Fig. 1. With the addition of silane terminated urethane to epoxy resin the impact strength of resultant hybrid increased considerably. The increase in the impact strength continued up to $10 \%$ STU addition. This was the highest impact value among the tested

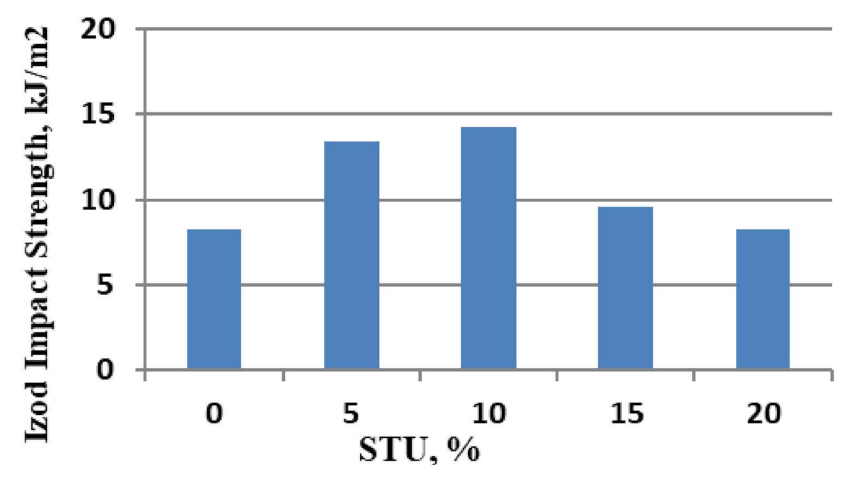

Fig. 1. Izod impact strength properties of epoxy + STU specimens.

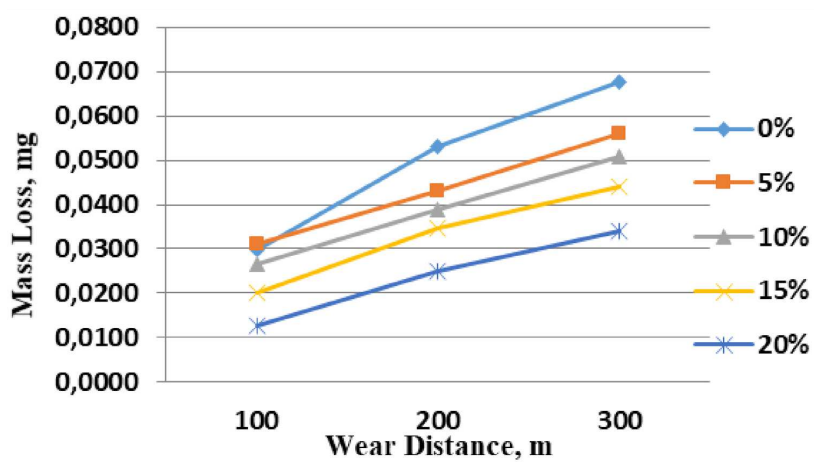

Fig. 2. Mass loss properties of epoxy + STU specimens.

hybrids. Beyond this point, impact strength of hybrids started to decrease with increased amount of STU. It is a well-known fact that in the toughening of epoxies through the addition of liquid rubbers such as CTBN and ATBN, there exist an optimum value of second phase [10].

The variation of mass loss for epoxy/STU hybrids with respect to the wear distance is shown in Fig. 2. Wear properties of hybrids are also highly influenced by the presence of silane in the hybrids [11]. The mass loss increased with increasing sliding distance. With the increasing amount of STU in the epoxy matrix, decreases in the amount of mass loss were observed.

The variation of wear resistance for epoxy/silica hybrids with respect to the wear distance is shown in Fig. 3.

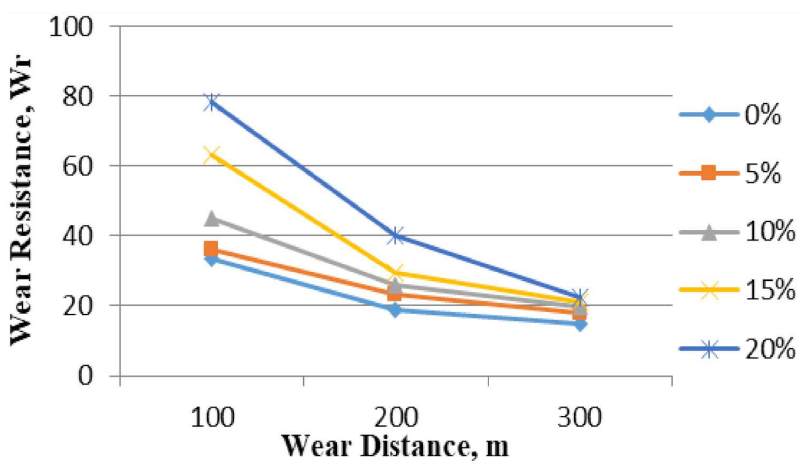

Fig. 3. Wear resistance properties of epoxy + STU specimens.

Two distinct regions were observed in wear rates. For all specimens the wear rates decreased up to a sliding distance of $200 \mathrm{~m}$ beyond which varied for specimens. After this point, the wear resistance caused a partial reduction in the wear rate values as the slip distances increased.

\section{Conclusion}

It was found that the incorporation of silane terminated polyurethane oligomer into epoxy resin was highly effective in toughening the epoxy resin. It is believed that an IPN structure was also present within the structure in addition to presence of a dispersed second phase. They were both active in toughening. For all specimens the wear rates decreased up to a sliding distance beyond After this point, the wear resistance caused a partial reduction in the wear rate values as the slip distances increased

\section{References}

[1] H. Yahyaie, M. Ebrahimi, H.V. Tahami, E. Mafi, P Org. Coat. 76, 286 (2013).

[2] A.J. Kinloch, R.J. Young, Fracture Behavior of Polymers, Elsevier Applied Science Publishers, London 1983.

[3] Y.F. Shih, R.J. Jeng, App. Poly. Sci. 86, 1904 (2002).

[4] H.J. Sue, P.M. Puckett, J.L. Bertram, L.L. Walker, The network structure of epoxy systems and its relationship to toughness and toughenability ACS Symp., 2000.

[5] H. Harani, S. Fellahi, M. Bakar, J Appl. Polym. Sci. 70, 2603 (1998).

[6] A. Zudeldia, M. Larranga, P. Remiro, I. Mondragon, J Appl. Polym. Sci B 42, 3920 (2004).

[7] S.P. Lin, J.L. Han, J.T. Yeh, F.C. Chang, K.H. Hsieh, E Poly J. 43, 996 (2007).

[8] L.H. Sperling, Interpenetrating polymer networks and related materials, Plenum Press, New York 1981.

[9] I. Kartal, A J Chem. 26, 6018 (2014).

[10] A.J. Kinloch, S.J. Shaw, D.A. Tod, D.L. Hunston, Polymer 24, 1341 (1983).

[11] E.T.N. Bisanda, M.P. Ansell, Comp. Sci. Tech. 41, 165 (1991). 